\title{
NUTRITIONAL FOLLOW-UP AFTER DISCHARGE OF MALNOURISHED GERIATRIC PATIENTS - DESIGN OF A RANDOMIZED CLINICAL STUDY
}

\author{
J.L. Pedersen ${ }^{1}$, P.U. Pedersen ${ }^{2}$, E.M. Damsgaard ${ }^{1}$
}

\begin{abstract}
Objective: The purpose of the study is to investigate the effect of two nutritional follow-up intervention. Methods: home visit and telephone follow-up, on ADL, physical function, quality of life, readmission, and mortality, and compare the interventions with no followup. This article describes the considerations behind the study design. Design: The study is a randomized clinical study. The randomization allocated participants to one of three groups: 'home visit', 'telephone consultation', or 'control'. Setting: Participants were recruited from two geriatric wards between May 2011 and October 2013. period fell eight weeks after discharge from hospital. Participants: Inclusion: Malnourished or at risk of malnutrition, 75+ years and older, home-dwelling, and living alone. Exclusion: Terminal illness, cognitive impairment, and nursing home resident. Intervention: Nutritional counselling after hospital discharge, based on individual nutritional needs identified during admission, and tailored to the individual's preferences and situation. The intervention was performed by a clinical dietician, and included the patient's daily home carer. The intervention took place 1 week, 2 weeks, and 4 weeks after discharge, either as face-to-face counselling in the patients' homes (home visit group), or via telephone (telephone consultation group). The control group received no followup after discharge. Measurements: Primary outcome is a change in ADL (Barthel-100), while secondary outcomes include other physical measurements (handgrip strength, 30-sec. chair stand test, CAS), quality of life and depression measurements (SF-36, Depression List, Geriatric Depression Score), and Avlund mobility-tiredness score. Other secondary outcome measures are readmission, and mortality rates at 30 and 90 days post-discharge. Conclusion: This randomized clinical trial will evaluate and compare two approaches to nutritional follow-up after discharge from hospital with no follow-up. It is expected that these interventions will prevent deterioration in physical function, which is significant in preventing further deterioration of physical, mental, and social functions, and reduce hospital readmissions and mortality.
\end{abstract}

Key words: Malnourished geriatric patients, nutritional counselling after discharge,home carer, physical functions, readmission.

\section{Introduction}

\section{The malnourished elderly}

The prevalence of malnutrition among older adults varies, depending on the definition on which the screening tools are based and the context; hospitalized, rehabilitation, nursing home resident, or home-dwelling elderly (1). The overall prevalence of malnourishment or risk of malnutrition is $23-33 \%$ and $46-52 \%$, respectively. Mean age in the two studies are 80.6 and 82.3 , respectively $(1,2)$. In community care, the prevalence of malnutrition is $6-15 \%(1,3,4)$ and the incidence is $7-16 \%$ (3). In hospital and rehabilitative settings, the

1. Aarhus University Hospital, Geriatrics, Aarhus, Denmark; 2. Center of Clinical Guidelines - Clearinghouse, Department of Health Science and Techonology, Aalborg University, Denmark

Corresponding Author: Jette Lindegaard Pedersen, Clinical research nurse, Aarhus University Hospital, Geriatrics, P.P. Oerumsgade 11, Aarhus, 8000, Denmark, jetpeder@rm.dk; lindegaardp@gmail.com prevalence of malnourishment and risk of malnutrition among the elderly is $85-90 \%(1,2)$, whereas no studies have documented the incidence of malnutrition among the elderly in the period following their discharge from hospital.

\section{Background}

\section{Definitions of malnutrition, undernutrition, and disease-related malnutrition}

The European Society for Clinical Nutrition and Metabolism (ESPEN) defines the term 'malnutrition' as deficiency, excess, or imbalance of protein, energy, and other nutrients, causing measurable adverse effects on tissues and function, and clinical outcome. The term 'undernutrition' is used for deficient protein and energy intake or absorption, and is often described as 'protein-energy malnutrition' (PEM) (5). Among elderly 
undernutrition occurs mainly in relation to diseases (disease-related malnutrition), and is characterized by weight loss, loss of body fat, and muscle tissue (6).

\section{Consequences of disease-related malnutrition}

The human body's response to critical illness involves increased metabolic activity, and decreased appetite and food intake. In a diseased state, the body's requirements for substrate to repair and restore damaged or impaired organs are met by a breakdown of tissue, especially muscle and fat. This loss of tissue affects the body on micro- and macro-levels, for example, the immune system and organs (6), and reduces functions such respiration, heart function, and mobility, thereby exposing the elderly to complications such as infection, poor wound healing, and fatigue (4). Malnutrition at admission is associated with poorer physical function at the time of discharge (7), resulting in delayed post-discharge recovery (8), reduction in day-to-day activities (9), poor self-care ability (10), difficulty with meal preparation (11), dependence on help from home care facilities, decreased quality of life (12), readmission (13), and death $(14,15)$. Unlike younger individuals, the elderly do not regain their appetite or resume their previous food intake when they recover (4), resulting in continued weight loss and diminished reserves to meet the future demands of diseases. This vicious cycle may worsen, owing to chronic and/or acute conditions including medical and social factors, inducing a downward spiral of readmissions to hospital, and the deterioration of physical, mental, and social functions.

\section{Nutritional intake among the elderly}

In a review of the literature, Nieuwenhuizen et. al. identified three factors affecting nutritional intake among the elderly: 1) personal, 2) food, and 3) environmental. Personal factors encompass physiological, psychological, and social changes that affect the eating process and energy intake. Food factors are limited by satiation (which leads the individual to stop eating) and satiety (which controls the interval between two successive meals). Protein has the highest degree of satiety, followed by carbohydrate, whereas fat is the least satiating macronutrient. Food factors that may increase energy intake are palatability, energy density, portion size and volume, liquid versus solid food, and viscosity of the food. Environmental factors play an important role in creating supportive eating environments, and include atmosphere, the presentation of the food, eating with others, timing of the meal, meeting food preferences, and sufficient assistance with the meal. In order to achieve increased nutritional intake among the elderly, Nieuwenhuizen et al. recommend focusing on the following items: 1) eating environment, 2) motivation and help from carer, 3) dietary advice, 4) fortified meals, and
5) small, energy-dense, oral nutrition supplements (16).

\section{Increased nutritional intake}

Several studies have been conducted to determine the effectiveness of nutritional interventions adding extra energy and/or protein, such as oral nutritional supplements (ONS), but only a few of these studies have shown functional improvements $(17,18)$ and reduced mortality $(18,19)$. Nutrition counselling studies have documented improvement in self-care ability (20) and mobility (21), but no reviews or meta-analyses have documented the effect of increased nutritional intake on physical function (22), quality of life (23), hospital readmission, or mortality (24). The Cochrane reviews draw no specific conclusions regarding recommendations for nutritional supplements $(23,25)$ or nutrition counselling (24) during recovery. Despite that, intervention seems to be better than no intervention, even though the precise contributions have not yet been determined (24).

Nutritional health in the elderly is multifaceted, and includes physiological, psychological, mental, and social factors (26). Therefore, it seems obvious to include multiple factors in the intervention, for the purpose of maintaining or postponing the deterioration of functions.

\section{Nutritional counselling}

In the literature, the terms 'nutritional counselling' and 'dietary advice' are used interchangeably. Nutritional counselling is defined as 'a supportive process to set priorities, establish goals, and create individualized action plans that acknowledge and fosters responsibility for self care' (27). Diet instructions and nutritional support are adapted to individual preferences and circumstances (individual, tailored intervention), to create meaningfulness that motivates a change from unfavourable eating and meal habits to healthy nutritional behaviour. Nutritional behaviour change therapy has already demonstrated positive results in weight management and prevention programmes for cardio-vascular diseases and diabetes 2 (27). Therefore, applying this approach to intervention related to diseaserelated malnutrition in the elderly seems advisable. Several studies have reported the use of nutritional counselling, but the considerations behind this approach, the content and process of the counselling sessions, are rarely described, and consequently appear unclear.

\section{Behavioural nutritional therapy}

Cognitive and behavioural theories and therapy (CBT) assume that behaviour is learned, and can be unlearned. CBT is based on the assumption that cognition (how we think), behaviour (how we act), emotions (how we 
feel), and environmental factors interact with each other (27). Michie et al. designed a framework for behaviour change, which includes three inter-related components of a behaviour: 1) the capability (the individual's psychological and physical capacity), 2) the opportunity (the factors that lie outside the individual), and 3) the motivation (28).

\section{Motivation}

Motivation is related to meaningfulness, and arises from within the person; it is not something that is done to the person. For example, motivating factors for nutritional behaviour change among the healthy elderly were identified as 'to remain healthy and independent' (29). The durability of cognitive and behavioural changes depends on the degree of active, rather than passive, participation of the elderly (30). Self-efficacy also seems to play a major role in facilitating dietary change, because self-efficacy reflects optimistic self-belief when overcoming a change in habits and routines (31).

\section{CBT strategies}

CBT strategies in nutrition counselling encompass goal setting, planning, problem solving, and environmental and social support (27). Problem solving is an ongoing process involving identification of barriers and solutions, implementation and evaluation of solutions, and adjusting strategies. Planning seems to be the mediator between intentions and behaviours, because intentions of good behaviour change seem more likely to be remembered and translated into action when turned into specific plans. Plans include specification of when, where, and how to carry out the plan (31). Structured meal plans increase adherence to the daily energy goal, because the detailed plans list exactly the types of food and portion sizes to be eaten (27). Structured meal plans simplify choices and facilitate the meal situation for the elderly. 'Meal replacement' means changing one food item from the diet plan with another containing the same amount of energy and/or protein. Meal replacement helps the elderly to vary and modify their meals and gain control, and thereby achieve behaviour change (27).

\section{Social and environmental support}

Family, network, and health care professionals can support the elderly in their dietary changes with information, encouragement, and emotional support. Home care staff are frequently in contact with the elderly, and possess a unique opportunity to stimulate, support, and encourage the elderly to optimize their daily nutritional intake, and create supportive eating environments.

\section{In Person versus telephone intervention}

Traditionally, nutritional counselling after discharging the elderly from hospital has been carried out as in-person counselling in the patients' homes. With short hospital stays, telephone follow-ups have been used in many health care settings, because they are easy to organize, less time consuming, and less expensive, compared to home visits (32). The question is whether telephone follow-up is suitable and effective for supporting the elderly who suffer from disease-related malnutrition.

\section{Objective}

The objective of this study is to investigate the effect of two nutritional follow-up intervention methods: home visit and telephone follow-up on physical function, quality of life, readmission, and mortality, and compare these interventions with no follow-up.

\section{Methods}

The study is a randomized clinical trial following-up on activities of daily living (ADL), physical function, and quality of life at the eight-week mark, and following-up on readmission and mortality at thirty and ninety days.

\section{Participants}

Patients eligible for inclusion were individuals aged 75 years and older, home dwelling, living alone, and malnourished or at risk of malnutrition. Patients who suffered from terminal illnesses or cognitive impairment, and nursing home residents were excluded. The setting for inclusion was at two geriatric wards at Aarhus University Hospital, Denmark. Both wards receive acute geriatric patients. At ward one, the patients suffer primarily from medical diseases, at ward two, the patients are primarily hip fracture patients.

\section{Recruitment}

Participants were consecutively recruited from ward one between May 2011 and October 2013, and from ward two between October 2011 and October 2013, except for a four-week period in the summer of 2013. Eligible patients were contacted by the primary investigator, who provided oral and written information. Time was given to reflect, or talk to relatives regarding participation, before informed consent was obtained.

\section{Randomization}

At discharge, the participants were stratified according to nutritional status: Mini Nutritional Assessment (MNA) 
below 17 points (malnourished) or MNA from 17 to 23.5 points (at risk of malnutrition). The randomization was executed electronically in the web-based, clinicaltrial support-system 'TrialPartner' (Public Health and Quality Improvement, Central Denmark Region). This central computer program uses permuted block sizes, and stratifies the randomization according to nutritional status, which allocates the participants to the 'home visit', 'telephone follow-up', or 'control' group (figure 1).

\section{Figure 1}

Study randomization

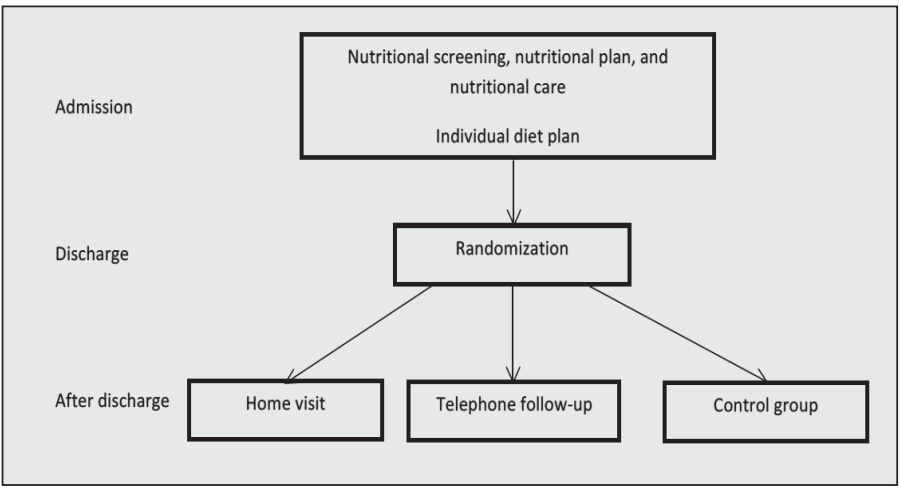

\section{Blinding}

Owing to the nature of the intervention, it was not possible to blind the participants to the intervention. The research assistant, who conducted the baseline and follow-up measures (week 0 and week 8 ), was not informed of the randomization, but it cannot be ruled out that the participants may have mentioned their allocation. The primary investigator obtained baseline characteristics before randomization, and from that point on, the primary investigator was not in contact with the participants.

\section{Standard care and intervention}

\section{Standard care during admission}

During admission, all patients received standard care, which encompasses a multi-professional, comprehensive geriatric assessment, including nutritional screening (33). Patients identified as being at nutritional risk received a nutrition plan, including estimates of energy and protein needs (34), nutritional therapy, recording of food and fluid intake for at least 3 days, and discharge arrangements with the home care facilities (35).

Simultaneously with the nutritional therapy, the comprehensive geriatric examination tried to detect and solve underlying causes of malnutrition (e.g. nausea, infection, depression, medication), and conducted discharge planning with the home care facilities. Discharge preparation includes assessments of individual needs for arrangements such as meal service, food delivery, and home care service to support daily meals. All patients receive an individual diet plan, and instruction in how to implement the plan for their individual preferences. The diet plan consists of three daily meals, three between-meal snacks, and supplements.

\section{After discharge}

At discharge, patients were randomized and allocated to the 'home visit', 'telephone follow-up' or 'control' group. After discharge, they received nutritional treatment according to their allocation.

\section{Intervention care}

Patients in the intervention groups received nutritional follow-up after discharge, conducted as nutritional counselling performed by a clinical dietician, either as in person counselling in the patient's home (home visit group) or as telephone consultation (telephone followup).

The intervention was based on nutritional needs identified during admission, and tailored to the individual's preferences and circumstances. Since reduced appetite and low food intake have become the normal situation, the intervention was focused on nutritional and meal behaviour that improve appetite and increase nutritional intake. The counselling sessions incorporate the participant's home carer, who holds a key position to supporting the participant on a daily basis.

\section{Control group}

The control group received standard care during admission and no follow-up after discharge.

\section{Intervention groups}

\section{Intervention structure}

Patients in the home visit group received in person counselling for an estimated 45 minutes each. The home carer was present, and participated in the session. In the telephone group, the counselling sessions were performed via telephone, for an estimated 15 minutes. The home carer was present in the participant's home, and was invited to talk to the clinical dietician via telephone. In both groups, the first counselling session took place one week after discharge, the second session took place two weeks after discharge, and the third session took place four weeks after discharge (figure 2). Between the interventions, the participant and the home carers could contact the clinical dietician via telephone, to solve unanswered questions. The content and extent of this contact was documented. 
Figure 2

Graphical depiction of interventions

\begin{tabular}{|c|c|c|c|c|}
\hline \multicolumn{2}{|c|}{ Time line } & \multicolumn{3}{|c|}{ Nutritional care and measurements } \\
\hline \multicolumn{2}{|c|}{ Admission } & \multicolumn{3}{|c|}{ Nutritional screening \& nutritional plan } \\
\hline \multicolumn{2}{|c|}{ Discharge } & \multirow{2}{*}{\multicolumn{3}{|c|}{$\begin{array}{l}\text { Baseline characteristics } \\
\text { Baseline measurements }\end{array}$}} \\
\hline & & & & \\
\hline \multicolumn{2}{|c|}{ Randomization } & Home visit & $\begin{array}{l}\text { Telephone } \\
\text { follow-up }\end{array}$ & Control \\
\hline \multicolumn{2}{|c|}{ After discharge } & & & \\
\hline \multicolumn{2}{|l|}{2 weeks } & & c & \\
\hline \multicolumn{2}{|l|}{4 weeks } & & c & \\
\hline \multicolumn{2}{|l|}{30 days } & \multicolumn{3}{|c|}{ Recording of readmission and mortality outcomes } \\
\hline \multicolumn{2}{|l|}{8 weeks } & \multicolumn{3}{|c|}{ Follow-up measurement of outcomes } \\
\hline \multicolumn{2}{|l|}{90 days } & \multicolumn{3}{|c|}{ Recording of readmission and mortality outcomes } \\
\hline \multirow[t]{2}{*}{$\mathrm{a}$} & \multicolumn{4}{|c|}{$\begin{array}{l}\text { Individual diet plan handed out and reviewed before discharge. The } \\
\text { diet plan is in accordance with the patient's individual energy needs. } \\
\text { The diet plan encompasses } 3 \text { daily meals, } 3 \text { between-meal snacks, } \\
\text { and supplements. }\end{array}$} \\
\hline & \multicolumn{4}{|c|}{$\begin{array}{l}\text { Home visit by clinical dietician who provides nutritional counselling } \\
\text { based on the patient's individual preferences and diet plan. The } \\
\text { counselling session is estimated at } 45 \text { minutes. The patient's home } \\
\text { care provider participates in the counselling session. }\end{array}$} \\
\hline c & \multicolumn{4}{|c|}{$\begin{array}{l}\text { Telephone follow-up by clinical dietician who provides nutritional } \\
\text { counselling based on the patient's individual preferences and diet } \\
\text { plan. The counselling session is estimated at } 15 \text { minutes. The } \\
\text { patient's home care provider is present in the patient's home and } \\
\text { speaks with the dietician via telephone. }\end{array}$} \\
\hline
\end{tabular}

The time of the first counselling session was agreed upon between the clinical dietician and the leader of local home care, and was scheduled in the home carer's work plan. Management of the municipal home health care supported the study by providing the home carer with extra time to participate in the counselling sessions.

Patients were contacted by the same dietician throughout all three interventions. Deviations from the intervention protocol were immediately reported to the primary investigator and documented. Once a week, the dietician and the primary investigator held study protocol meetings, to discuss and adjust the course of the intervention.

\section{Intervention content}

Each counselling session was guided by a questionnaire, conducted as an interview, and filled up by the dietician.

The questionnaire included the following items:

1. Status of the nutritional situation since discharge/ previous session, including the participants' specification of nutritional intake. Is the intake consistent with the diet plan? Is the intake more or less, or does the participant use meal replacements?

2. Identify inhibiting and restraining elements, and conditions that contribute to the reduced intake of food and fluid. Identify health-promoting behaviour, and conditions that contribute to the improved intake of food and fluid.

3. Support health promoting behaviour, and encourage the participant to overcome negative conditions.

4. In cooperation with the participant, adjust the nutrition plan (e.g. what, how, and when to intake food and fluid).

5. Encourage, support, and stimulate the participant and the home carer to follow the nutrition plan.

\section{Outcomes}

Baseline characteristics were obtained at hospital before discharge. For each patient, baseline characteristics are registered in medical records and/or interview: age, gender, diagnosis, co-morbidity, nutritional status, oral and dental status, functional status, and availability of help from home care facilities at the time of admission and discharge. Baseline measures (week 0 ) and follow-up measures (8 weeks) were performed in the participants' homes by a research assistant.

Primary outcome:

- Change in ADL (Barthel-100 score) between 0 and 8 weeks post-discharge.

Secondary outcome

- Change in the 30-second chair stand test, handgrip strength, Cumulated Ambulation Score (CAS), and Avlund mobility-tiredness scale (Mob-T) between 0 and 8 weeks post-discharge.

- Change in health-related quality of life (SF-36), Depression List (DL), and Geriatric Depression Score (GDS) between 0 and 8 weeks post-discharge.

- Readmissions at 30 and 90 days after discharge.

- Mortality at 30 and 90 days after discharge.

\section{Measurements}

The measurements chosen were all validated for use with the elderly population. All questionnaires were performed as structured interviews.

\section{The Modified Barthel-100 Index (MBI)}

MBI is a 10-item instrument that provides a score of basic daily activities (feeding, bathing, grooming, dressing, bowels, bladder, toilet use, transfer, mobility, and climbing stairs). The scores range from $0-100$, with a higher score indicating greater independence (36). 


\section{The 30-second chair stand test}

The 30-second chair stand test measures lower body strength, determining the number of times the participant can fully stand up and sit down in 30 seconds, with the arms crossed over the chest (37).

\section{Handgrip strength}

Handgrip strength measures strength in the upper limb muscles, and is determined using Jamar handgrip dynamometry in a sitting position, and with the dominant hand and the elbow flexed at a $90^{\circ}$ angle. The highest of 3 readings is recorded (38).

\section{Cumulated Ambulation Score (CAS)}

CAS is assessed in transfer from supine-to-sitting-tosupine, transfer from sitting-to-standing-to-sitting, and walking. Each function is scored as; 'able to perform function independently' (2 points); 'only able to perform function with assistance from one or two people' (1 point), and 'unable to perform function despite assistance from two people' (0 points) (39).

\section{Health related quality of life (SF-36)}

SF-36 consists of eight multi-item scales: physical function; Role-Physical, physical pain, general health; mental health, vitality; social function, and RoleEmotional. The raw scores are transformed into two scores: a Physical Component Summary (PCS) and a Mental Component Summary (MCS) (40). Higher scores indicate better health-related quality of life. SF-36 has been validated for the elderly Danish population (41).

\section{Depression List (DL)}

DL is a fifteen-item questionnaire, designed to assess quality of life in frail nursing home residents. DL addresses emotional well-being, social relationships, life satisfaction, comfort, functional competence, and autonomy. The scale ranges from 0 (best quality of life) to score 30 (poorest quality of life) $(42,43)$.

\section{Geriatric Depression Score (GDS)}

GDS is a fifteen-item instrument designed to assess emotional well-being in the elderly population (44). The scores range from 0 to 15 , where 0 points indicate no depression, and 15 indicate severe depression. A Danish version was validated, and the test concluded that the GDS, performed as an interview, is suitable for detecting depression among the home-dwelling, cognitively intact elderly (70 years or older) (45).

\section{Avlund mobility-tiredness scale (Mob-T)}

Mob-T is a six-item, functional ability scale that evaluates fatigue related to mobility (transfer, walking indoors, going outdoors, walking outdoors in nice weather, walking outdoors in poor weather, and climbing stairs) (46). Items managed without fatigue count as two points, items managed with fatigue count as one point, and items that the elderly cannot manage count as zero. The maximum score of twelve points indicates no fatigue, whereas zero points indicates insuperable fatigue.

\section{Mini nutritional assessment (MNA)}

The MNA is an eighteen-item nutritional assessment tool that consists of four parts: 1) anthropometric measurements 2) global assessments, 3) dietary questionnaire, and 4) subjective assessment. The maximum score is 30 points. Scores $<17$ identify patients as malnourished, 17 to 23.5 points indicate risk of malnutrition, and 24 to 30 points categorize patients as well nourished $(47,48)$ (Figure 3).

Figure 3

Time of measurements

\begin{tabular}{|c|c|c|c|c|c|}
\hline $\begin{array}{l}\text { Time } \\
\text { Outcome } \\
\text { measure }\end{array}$ & \begin{tabular}{|l} 
Before \\
discharge from \\
hospital
\end{tabular} & $\begin{array}{l}0 \text { weeks after } \\
\text { discharge }\end{array}$ & $\begin{array}{l}30 \text { days after } \\
\text { discharge }\end{array}$ & $\begin{array}{l}8 \text { weeks after } \\
\text { discharge }\end{array}$ & $\begin{array}{l}90 \text { days after } \\
\text { discharge }\end{array}$ \\
\hline $\begin{array}{l}\text { Mini Nutritional } \\
\text { Assessment }\end{array}$ & $x$ & & & $x$ & \\
\hline $\begin{array}{l}\text { Baseline } \\
\text { characteristics }\end{array}$ & $x$ & & & & \\
\hline $\begin{array}{l}\text { Baseline } \\
\text { measurements }\end{array}$ & & $x$ & & & \\
\hline $\begin{array}{l}\text { Follow-up } \\
\text { measurements }\end{array}$ & & & & $x$ & \\
\hline Readmission & & & $x$ & & $x$ \\
\hline Mortality & & & $x$ & & $x$ \\
\hline
\end{tabular}

\section{Ethics}

Informed, written consent was obtained from the participants before their discharge from the hospital. The study was approved by the Danish Data Protection Agency, journal no. 2014-41-3221, and the Ethical Committee of Central Denmark Region, journal no. M-20100201. Trial registration: Clinical.Trials.gov, NCT01345032

\section{Sample size and data analysis}

\section{Power calculation}

A 10 point difference in the Barthel-100 score is regarded as a clinically relevant change. Significance level was set at 0.05, and the power at 0.90 (SD 11). Based on an unpublished rehabilitation project, the number of participants needed is calculated as $144-48$ in each of the $3 \mathrm{arms}$ - in order to detect a 10 point difference in change 97 
visit', and the control. Assuming that $25 \%$ are lost during follow-up, 192 patients were calculated to be included in the study.

\section{Data analysis}

All data will be entered twice in EPI Data, and STATA 13.1 will be used for statistical evaluation. Both descriptive and analytic analysis will be performed. The principle of repeated measurements will be used to analyse continuous variable, and variables with dichotomous outcomes will be analysed using the Chisquare test or Fisher's exact test. Intention-to-treat (ITT) and per protocol (PP) analysis will be performed.

\section{Discussion}

During admission and after discharge, standard nutritional care is supposed to prevent physical, mental, and social decline in the newly discharged patient. Despite that, the high prevalence of malnutrition (1) indicates that this care does not meet its purpose. As the length of hospital stays is reduced all over the world, new means of continuing nutritional support after discharge are needed. The present study is designed to strengthen the nutritional interventions implemented during the hospital stay, and combine them with existing support from the Danish primary health care system. The nutritional care in Danish hospitals encompasses nutritional screening at admission (according to NSR2002 (33)), a nutrition plan and therapy during admission, and at discharge, community home care is informed of nutritional status and recommendations after discharge (35). After discharge, the local home care authority can offer meal support provided by home care staff (e.g. support to reheat and arrange meals, support during the meal) and meals on wheels. This call raises the question of whether current standard nutritional care, or compliance with the care, is sufficient for the newly discharged, elderly patient who suffers from diseaserelated malnutrition. It may be asked whether these patients are able to care for their own nutritional needs. And, is the help they get sufficient?

The intervention started one week after discharge, when the participant was well established at home and receptive to the intervention, was resumed after two weeks, to keep the intervention on track, and was completed after four weeks. These points were chosen because many individuals encounter problems within the first week (49), and 4 to 6 weeks after discharge from hospital (50). The short-term intervention is supposed to prevent early nutritional problems that may lead to deterioration in physical function, early readmission, and death. Previous long-term nutritional studies documented post-discharge mortality rates in this group at $16 \%(20)$ and $17 \%$ (51) at 4 and 6 months, respectively, indicating that the early post-discharge period is critical for the frail elderly patients.

\section{Study population}

The population studied here is the malnourished elderly, 75 years and older, who are home-dwelling, living alone, newly discharged, and recovering from diseases.

The elderly who live alone are particularly vulnerable to malnutrition $(26,52-54)$. Losing a spouse is especially associated with poor eating behaviour (eating alone, skipping meals, low food diversity) and decreased nutrient intake (55).

Patients who suffer from cognitive impairment or terminal illnesses, and nursing home residents were excluded. Nursing home residents were excluded, because unlike home-dwelling elderly, they have access to nursing staff 24 hours a day. Patients who suffer from cognitive impairment were excluded, because the nature of the intervention requires the patients to adapt to cognitive therapy. Patients were identified as cognitively impaired when diagnosed as such by medical staff, or the Mini Mental statement Examination (MMSE) score was below 22.

\section{Internal validity}

In designing this study, protocols were considered, regarding the target population, recruitment, the intervention, the measurements and data collection, which contribute to the validity of the study. Strengths and weaknesses of this study will be described.

\section{Randomization and restriction}

In order enhance the validity of the study, and prevent bias and confounding, several strategies were applied to the study. One strategy is randomization, which, in relation to nutritional status, allocates the participants randomly to one of three groups, and in that way, balances confounding and the comparability between groups. The randomization method is web-based, conducted by an independent external organization.

Another strategy used is restriction. Individuals who live alone are at greater risk of malnutrition, compared to individuals who live with another person. This may be due to mutual support between the partners. To prevent this, the study is strictly restricted to the elderly who live alone (56).

\section{Data collection}

The participants were included consecutively, meaning that all patients who met the inclusion criteria throughout the study period were included, thus eliminating selection bias. 
Malnutrition and the consequences of malnutrition may have a number of sources, such as medical, physical and mental conditions, and medication. A comprehensive, multidisciplinary, geriatric assessment eliminates some of the confounding elements. To reduce inter-rater variability, the baseline and the follow-up measurements were determined by a few well-trained research assistants. The two examinations for each patient were made by the same research assistant, to minimize observer bias.

The questionnaires were presented during interviews, and filled up by the research assistant, to enhance the response rate.

\section{The intervention}

A strength of this study is that the complex intervention was based on a tested frame of reference and detailed description, which improves the transparency of the study.

The intervention addresses behaviour changes in food and meal habits, which are established at an early age, and are subject to a range of cultural, environmental, and circumstantial factors, and complicated by effects of disease. Furthermore, dietary interventions in nutritional support for the elderly often conflict with established healthy eating messages targeted at younger individuals, which may confuse the participant and the home carer. The intervention was individualized, and based on nutritional behaviour change theory and strategies that strengthen the study.

Including the home carer in the nutritional care process was a unique opportunity to support and encourage the participants to optimize their daily nutritional intake, and create supportive eating environments. The question is whether Danish home carers, who are trained in care of the healthy, home-dwelling elderly, posses the necessary knowledge and qualifications to effectively support the nutritional-at-risk elderly. Participating in counselling sessions with the elderly patient and the clinical dietician may provide the home carer with the knowledge needed in this specific care situation. In order to enhance the home carer's adherence to the intervention, agreements are made with the management of community health care.

Nutritional counselling after discharge is conducted as in person or over telephone counselling. A systematic literature review of telemedicine and telecare for older patients identified 68 studies with interventions taking place in the patients' homes. The majority of the studies included patients between 60 and 69 years (35 studies) and patients between 70 and 79 years (24 studies), whereas only one study included patients 80 and older (57). The question is whether telephone follow-up is suitable and effective for supporting the elderly who suffer from disease-related malnutrition.

\section{The measurements}

A strength of this study is its use of measurements and questionnaires, all of which are well-validated for the elderly population, and have been shown to capture the expected changes.

The physical measurements were chosen to detect a diversity of changes in physical function. The MBI measures disability, and reflects the overall activities of daily living. In this study, the MBI is administered as a combination of observation and in person interviews (36). The 30-second chair stand reflects lower body strength, and handgrip strength reflects upper body strength. Nutritional studies have documented low grip strength as predictive of decreased physical function, disability, morbidity, and mortality (38). The CAS score is developed to evaluate the ambulatory capacity in the early post-operative phase following hip fracture surgery. The CAS index predicts length of stay at hospital, discharge status, postoperative complications, and 30-day mortality (39). Because the CAS measures early postsurgery, basic ambulation skills, it may have produced a ceiling effect in the patients in this study. On the other hand, the measurements may reflect the diversity of patients included in the study.

\section{Blinding}

Owing to the nature of this study, it was not possible to blind the participants to the intervention. The primary investigator recruited the participants, collected baseline data before randomization, and conducted the randomization at discharge. After that time, the primary investigator was not in contact with the participants. The analysis will be conducted by the primary investigator, who is not blinded to participant allocation, which is a limitation of this study. The research assistant collected baseline and follow-up measurements. She was not informed of the allocation of the participants, but that the participants may have mentioned their allocation cannot be ruled out, which is also a limitation of this study.

\section{Analysis}

Intention-to-treat (ITT) and per protocol (PP) analysis will be performed. The Consort Statement recommends ITT analysis in randomized, controlled trials (58), because it reflects the effectiveness of the treatment with patient drop out. The ITT analysis is a statistical concept that tries to solve the problems of noncompliance and missing outcomes (59), but indicates very little about the efficacy. The efficacy of a treatment is best analysed by PP analysis, including participants who, comply fully with the allocated treatment. It is stated that before evaluating treatment effectiveness, it is necessary to establish treatment efficacy (60). However, the problem with the 
PP analysis is that the effects in patients who are not considered in the analysis are unknown (61).

\section{External validity}

A strength of this study is the wide range of medical conditions among the patients admitted to the two geriatric wards. Generalized conclusions cannot be drawn until this study is completed, because the analysis may reveal circumstances that have an impact on the generalizability of the study.

\section{Conclusion}

In this randomized clinical trial, the effect of two nutritional follow-up methods will be evaluated and compared with no follow-up on the malnourished elderly, following their discharge from hospital. Change in physical function and health-related quality of life, readmission, and mortality will be determined between the groups.

Conflict of Interest: There is no conflict of interest to declare.

\section{References}

1. Kaiser MJ, Bauer JM, Ramsch C, Uter W, Guigoz Y, Cederholm T, et al. Frequency of malnutrition in older adults: a multinational perspective using the mini nutritional assessment. J Am Geriatr Soc 2010 Sep;58(9):1734-1738.

2. Charlton KE, Nichols C, Bowden S, Lambert K, Barone L, Mason M, et al. Older rehabilitation patients are at high risk of malnutrition: evidence from a large Australian database. J Nutr Health Aging 2010 Oct;14(8):622-628.

3. Johansson Y, Bachrach-Lindström M, Carstensen J, Ek A. Malnutrition in a home-living older population: prevalence, incidence and risk factors. A prospective study. J Clin Nurs 2009 05;18(9):1354-1364.

4. MacIntosh C, Morley JE, Chapman IM. The anorexia of aging. Nutrition 2000 Oct;16(10):983-995.

5. Volkert D, Berner YN, Berry E, Cederholm T, Coti Bertrand P, Milne A, et al. ESPEN guidelines on enteral nutrition: geriatrics. Clin Nutr 2006 04;25(2):330360.

6. Stanga Z, Allison S, Vandewoude M, Schneider SM. Nutrition in the elderly. In: Sobotka L, editor. Basics in Clinical Nutrition: Publishing House Galén, Prague; 2011. p. 540-563.

7. Lee J, Higgins PA. Predicting posthospital recovery of physical function among older adults after lower extremity surgery in a short-stay skilled nursing facility. Rehabil Nurs 2008 Jul-Aug;33(4):170-177.

8. Neumann SA, Miller MD, Daniels L, Crotty M. Nutritional status and clinical outcomes of older patients in rehabilitation. J Hum Nutr Diet 2005 Apr;18(2):129-136.

9. Sorbye LW, Schroll M, Finne Soveri H, Jonsson PV, Topinkova E, Ljunggren $\mathrm{G}$, et al. Unintended weight loss in the elderly living at home: the aged in Home Care Project (AdHOC). J Nutr Health Aging 2008 Jan;12(1):10-16.

10. Dale B, Soderhamn U, Soderhamn O. Self-care ability among home-dwelling older people in rural areas in southern Norway. Scand J Caring Sci 2012 Mar;26(1):113-122.

11. Iizaka S, Tadaka E, Sanada H. Comprehensive assessment of nutritional status and associated factors in the healthy, community-dwelling elderly. Geriatr Gerontol Int 2008 Mar;8(1):24-31.

12. Gariballa S, Forster S. Dietary supplementation and quality of life of older patients: a randomized, double-blind, placebo-controlled trial. J Am Geriatr Soc 2007 Dec;55(12):2030-2034.

13. Vecchiarino P, Bohannon RW, Ferullo J, Maljanian R. Short-term outcomes and their predictors for patients hospitalized with community-acquired pneumonia. Heart Lung 2004 Sep-Oct;33(5):301-307.

14. Soderstrom L, Rosenblad A, Adolfsson ET, Saletti A, Bergkvist L. Nutritional status predicts preterm death in older people: a prospective cohort study. Clin Nutr 2014 Apr;33(2):354-359.

15. Yang Y, Brown CJ, Burgio KL, Kilgore ML, Ritchie CS, Roth DL, et al. Undernutrition at baseline and health services utilization and mortality over a 1-year period in older adults receiving Medicare home health services. J Am Med Dir Assoc 2011 May;12(4):287-294.

16. Nieuwenhuizen WF, Weenen H, Rigby P, Hetherington MM. Older adults and patients in need of nutritional support: Review of current treatment options and factors influencing nutritional intake. Clin Nutr 2010 /;29(2):160169.

17. Price R, Daly F, Pennington CR, McMurdo MET. Nutritional Supplementation of Very Old People at Hospital Discharge Increases Muscle Strength: A Randomised Controlled Trial. Gerontology 2005 May/ Jun;51(3):179.

18. Potter JM, Roberts MA, McColl JH, Reilly JJ. Protein energy supplements in unwell elderly patients--a randomized controlled trial. JPEN J Parenter Enteral Nutr 2001 Nov-Dec;25(6):323-329.

19. Potter JM. Oral supplements in the elderly. Curr Opin Clin Nutr Metab Care 2001 Jan;4(1):21-28.

20. Persson M, Ulander K. Nutrition monitoring of geriatric patients. Geneva, Switzerland: International Council of Nurses; 2001.

21. Beck AM, Kjaer S, Hansen BS, Storm RL, Thal-Jantzen K, Bitz C. Followup home visits with registered dietitians have a positive effect on the functional and nutritional status of geriatric medical patients after discharge: a randomized controlled trial. Clin Rehabil 2013 Jun;27(6):483-493.

22. Beck AM, Holst M, Rasmussen HH. Oral nutritional support of older (65 years + ) medical and surgical patients after discharge from hospital: systematic review and meta-analysis of randomized controlled trials. Clin Rehabil 2013 Jan;27(1):19-27.

23. Milne AC, Potter J, Vivanti A, Avenell A. Protein and energy supplementation in elderly people at risk from malnutrition. Cochrane Database Syst Rev 2009 Apr 15;(2)(2):CD003288.

24. Baldwin C, Weekes CE. Dietary advice for illness-related malnutrition in adults. Cochrane Database Syst Rev 2008 Jan 23;(1):CD002008. doi(1):CD002008

25. Avenell A, Handoll HH. Nutritional supplementation for hip fracture aftercare in older people. Cochrane Database Syst Rev 2010 Jan 20;(1):CD001880. doi(1):CD001880.

26. Callen BL, Wells TJ. Views of community-dwelling, old-old people on barriers and aids to nutritional health. J Nurs Scholarsh 2003;35(3):257-262.

27. Spahn JM, Reeves RS, Keim KS, Laquatra I, Kellogg M, Jortberg B, et al. State of the evidence regarding behavior change theories and strategies in nutrition counseling to facilitate health and food behavior change. J Am Diet Assoc 2010 Jun;110(6):879-891.

28. Michie S, van Stralen MM, West R. The behaviour change wheel: a new method for characterising and designing behaviour change interventions. Implement Sci 2011 Apr 23;6:42-5908-6-42.

29. Greaney ML, Lees FD, Greene GW, Clark PG. What older adults find useful for maintaining healthy eating and exercise habits. J Nutr Elder 2004;24(2):1935.

30. Green LW, Kreuter MW. Health Promotion Planning An Educational and Environmental Approach. Second Edition ed. Mountain View, California: Mayfiels Publishing Company; 2000.

31. Kreausukon P, Gellert P, Lippke S, Schwarzer R. Planning and self-efficacy can increase fruit and vegetable consumption: a randomized controlled trial. J Behav Med 2012 Aug;35(4):443-451.

32. Marshall S, Bauer J, Isenring E. The consequences of malnutrition following discharge from rehabilitation to the community: a systematic review of current evidence in older adults. J Hum Nutr Diet 2014 Apr;27(2):133-141.

33. Kondrup J, Rasmussen HH, Hamberg O, Stanga Z, Ad Hoc ESPEN Working Group. Nutritional risk screening (NRS 2002): a new method based on an analysis of controlled clinical trials. Clin Nutr 2003 Jun;22(3):321-336.

34. Nordic nutrition recommendations 2012 - integrating nutrition and physical activity. : Norden.

35. Sundhedsstyrelsen. Screening og behandling af patienter i ernæringsmæssig risiko. Vejledning til læger, sygeplejersker, social- og sundhedsassistenter, sygehjælpere og kliniske diætister. 2008.

36. Shah S, Vanclay F, Cooper B. Improving the sensitivity of the Barthel Index for stroke rehabilitation. J Clin Epidemiol 1989;42(8):703-709.

37. Jones CJ, Rikli RE, Beam WC. A 30-s chair-stand test as a measure of lower body strength in community-residing older adults. Res Q Exerc Sport 1999 Jun;70(2):113-119.

38. Norman K, Stobaus N, Gonzalez MC, Schulzke JD, Pirlich M. Hand grip strength: outcome predictor and marker of nutritional status. Clin Nutr 2011 Apr;30(2):135-142.

39. Foss NB, Kristensen MT, Kehlet H. Prediction of postoperative morbidity, mortality and rehabilitation in hip fracture patients: the cumulated ambulation score. Clin Rehabil 2006 Aug;20(8):701-708.

40. Ware JE,Jr, Sherbourne CD. The MOS 36-item short-form health survey (SF-36). I. Conceptual framework and item selection. Med Care 1992 Jun;30(6):473-483.

41. Bjørner JB. Dansk manual til SF-36: et spørgeskema om helbredsstatus. 1997:143 s.

42. Gerritsen DL, Steverink N, Ooms ME, Ribbe MW. Finding a useful conceptual basis for enhancing the quality of life of nursing home residents. Qual Life Res 2004 Apr;13(3):611-624.

43. Gerritsen DL, Steverink N, Ooms ME, de Vet HC, Ribbe MW. Measurement of overall quality of life in nursing homes through self-report: the role of cognitive impairment. Qual Life Res 2007 Aug;16(6):1029-1037. 
44. Sheikh JI, Yesavage JA. Geriatric Depression Scale: recent evidence and development of a shorter version. In: Brink TL, editor. Clinical gerontology: a guide to assessment and intervention New York: Hawthorn Press; 1986. p. 165-173.

45. Djernes JK, Kvist E, Olesen F, Munk-Jorgensen P, Gulmann NC. Validation of a Danish translation of Geriatric Depression Scale-15 as a screening tool for depression among frail elderly living at home. Ugeskr Laeger 2004 Mar 1;166(10):905-909.

46. Avlund K, Kreiner S, Schultz-Larsen K. Functional ability scale for the elderly - a validation study. European Journal of Public Health 1996;6(1):35-42.

47. Guigoz Y, Lauque S, Vellas BJ. Identifying the elderly at risk for malnutrition: The Mini Nutritional Assessment. Clin Geriatr Med 2002 11;18(4):737-757.

48. Vellas B, Guigoz Y, Garry PJ, Nourhashemi F, Bennahum D, Lauque S, et al. The Mini Nutritional Assessment (MNA) and its use in grading the nutritional state of elderly patients. Nutrition 1999 Feb;15(2):116-122.

49. Mistiaen P, Poot E. Telephone follow-up, initiated by a hospital-based health professional, for postdischarge problems in patients discharged from hospital to home. Cochrane Database Syst Rev 2006 Oct 18;(4)(4):CD004510.

50. Naylor MD. Transitional care of older adults. Annu Rev Nurs Res 2002;20:127-147.

51. Volkert D, Hübsh S, Oster P, Schlierf G. Nutritional support and functional status in undernourished geriatric patients during hospitalization and 6-month follow-up. Aging Clin.Exp.Res. 1996;8:386-395.

52. Pirlich M, Schutz T, Kemps M, Luhman N, Minko N, Lubke HJ, et al. Social risk factors for hospital malnutrition. Nutrition 2005 Mar;21(3):295-300.
53. Chen CC, Tang ST, Wang C, Huang G. Trajectory and determinants of nutritional health in older patients during and six-month posthospitalisation. J Clin Nurs 2009;18(23):3299-3307.

54. Kharicha K, Iliffe S, Harari D, Swift C, Gillmann G, Stuck AE. Health risk appraisal in older people 1: are older people living alone an «at-risk» group? Br J Gen Pract 2007 Apr;57(537):271-276.

55. Stahl ST, Schulz R. Changes in routine health behaviors following late-life bereavement: a systematic review. J Behav Med 2014 Aug;37(4):736-755.

56. Rothman KJ. Epidemiology : an introduction. 2nd ed. Oxford; New York: Oxford University Press; 2012.

57. van den Berg N, Schumann M, Kraft K, Hoffmann W. Telemedicine and telecare for older patients-A systematic review. Maturitas 2012 10;73(2):94114.

58. Boutron I, Moher D, Altman DG, Schulz KF, Ravaud P, CONSORT Group. Extending the CONSORT statement to randomized trials of nonpharmacologic treatment: explanation and elaboration. Ann Intern Med 2008 Feb 19;148(4):295-309.

59. Gupta SK. Intention-to-treat concept: A review. Perspect Clin Res 2011 Jul;2(3):109-112.

60. Armijo-Olivo S, Warren S, Magee D. Intention to treat analysis, compliance, drop-outs and how to deal with missing data in clinical research: a review. PHYS THER REV 2009 02;14(1):36-49.

61. Kirkwood BR, Sterne JAC. Essential medical statistics. 2nd ed. Malden, Mass.: Blackwell Science; 2003 